Editorial

\title{
Partnerships for scaled online learning and the unbundling of the traditional university
}

\author{
Henk Huijser \\ Learning and Teaching Unit, Queensland University of Technology, Australia \\ Rachel Fitzgerald \\ UQ Business School, University of Queensland, Australia
}

Gilly Salmon

Education Alchemists Ltd; Swinburne University of Technology

\begin{abstract}
This special issue is about partnerships for scaled online learning and the unbundling of the traditional university. We are excited by the emerging models that are showcased; they are more diverse than we had originally envisaged. We hope this issue will be considered by readers as a valuable and timely contribution to a wider conversation about partnership and unbundling. There are clearly opportunities for creative and transformational thinking and practice as we move towards a more digitally integrated future for higher education. In this editorial, we outline the varied contributions and place them in the context of a wider discussion about higher education, for now and for a post-COVID world.
\end{abstract}

Keywords: partnerships, scaled online learning, unbundling, higher education, online programme management

\section{Introduction}

As editors of this special issue, we sought to explore the implications for universities and their students when broad areas of institutions' core activities are divided into key elements and delivered through partnership arrangements, an approach often referred to as unbundling (Lewis \& Shore, 2019; Neely \& Tucker, 2010; Swinnerton et al., 2018; Wang, 1981). These key components include marketing and enrolment and the design and building of academic course experiences, as well as students' pastoral and academic support. They are complex and significant learning and teaching activities that go well beyond the provision of technology platforms.

Information technology support services and technology platforms have often been delivered through a range of partnerships. This has been typical for learning management systems (often called virtual learning environments) almost since their inception more than 20 years ago. However, such arrangements run along a continuum from very small-scale commercial partnerships, such as a limited number of subscriptions for software applications, to much more comprehensive partnerships, including long-term contractual agreements that bind partners to particular agreements for a number of years. With the recent major push to generate high-quality digital learning, partnerships have become even more common and significant in higher education. The growth in partnerships is related to the core business of universities, that is, formal teaching programs and courses. Massive open online courses (MOOCS) present a somewhat different scenario for now, but this may change as they develop into the future and as new business models are developed around them.

The objective for this special issue of AJET was to explore and extend the concept of partnership, highlighting more recent approaches within the sector. In response to the call for papers, the diverse submissions showcased embedded, almost cultural, differences between universities' approaches to development, evaluation and feedback on the one hand, and those of commercial organisations on the other.

We thank everyone involved in this special issue for their openness about their partnerships, which has enabled us to publish these papers and shine a light on the current multiplicity of practices. Our hope is that these articles will enable more effective partnerships, and ultimately impact on widening participation and improved access to quality online courses. As we complete and prepare for publication with the pandemic 
still raging worldwide, interest has increased significantly towards flexible and digital learning. We believe that as emergency remote teaching turns to high-quality sustainable online education, every institution will be considering how best to achieve a response. It seems likely partnerships will be put firmly back on the agenda, and the contributors here have true hindsight and foresights to offer.

We aimed to focus on partnership opportunities, while at the same time creating a space to critique elements that could be significantly improved. We believe that public-private partnerships look likely to increase in the wake of pandemic-related pivots online and with the growth of different approaches to the curriculum, such as credit-bearing micro-credentials, as part of higher education qualifications (Oliver, 2019). In this special issue, we therefore looked for contributions from early adopters to discuss challenges faced, mitigation and plans, as a foundation for future practice and research.

\section{Inside this special issue}

The articles demonstrate that the concept of partnership can be interpreted broadly and in diverse ways, providing insights into different models. We therefore offer an extension of a single model of one institution and one commercial partner within public-private consortia to a broader view.

Models include Roisin Donnelly and Terry Maguire's look at creating an Irish national partnership for the development of educators in higher education through micro-credentials. Their paper considers the design of such a partnership and the differences that emerged around recognition and accreditation. Angelica Risquez, Dara Cassidy, and Gearóid Ó Súilleabháin evaluate the same national partnership but with a focus on the professionalisation of teaching and learning using digital badges. They acknowledge the power of national partnerships in creating meaningful awards for learners.

We noted that when collaborations are configured thoughtfully and are open to continuous evaluation and improvement, genuine opportunities to develop accessible educational experiences are demonstrated. Indeed, these might further fulfil the social purposes of higher education and the affordance of inclusive opportunities. For example, Chris Walsh, Abhinav Mital, Michael Ratcliff, Ana Yap, and Zeina Jamaleddine present an innovative public-private partnership in the Australian context with a commercial organisation that provides personalised academic student support, targeting online learners by deploying learning analytics. The partnership is unbundled and demonstrates positive impacts on student retention and satisfaction. The design and delivery of the online courses is managed by a wholly-university-owned subsidiary. The partner provides front-line facilitator support 7 days a week to ensure that students are engaged and that their immediate needs are met. Analytics are used to identify and target specific students at times where additional support is required. Student feedback about this facilitation model is highly positive.

Gail Wilson, Andrew McAuley, Sally Ashton-Hay, and Tina Van Eyk discuss the journey they embarked upon with an external partner to provide learning support for students at Southern Cross University in Australia. Developing trust in the partnership on both sides presented significant challenges, some of which are yet to be resolved. However, the partnership has evolved over the last few years to the mutual benefit of both organisations: students received support and feedback "just when they needed it most", academic staff revitalised coursework, and the partner fine-tuned a targeted service for the university. The authors point to benefits for all stakeholders, which stem from a collaboration-based approach involving a partner with an openness and willingness to succeed on both sides. Their case study offers implications for practice and policy across the higher education sector.

Henk Huijser and Rachel Fitzgerald find similar results in their case study at a university in Australia which is in the early stages of a public-private partnership. They note concerns from their academic community about the impact that such partnerships may have on educational quality, academic freedom and university reputation, but they also find that shared governance, open communication and the willingness to succeed may mitigate these anxieties.

Openness and willingness to succeed is a recurrent theme, including in the paper by Paula Shaw, Marlies Gration, Pauline Green, Christine Rhodes, David Sheffield, and Julie Stone. They trace the history and evolution of an online learning internal partnership at the University of Derby in the United Kingdom. Their model was a response to an initial situation where online learning was organisationally positioned within 
individual faculties, which they call their "unbundled" model, to a "rebundled" online learning model. A central, specialist university department is responsible for the development and quality of the whole university's online learning, including related data capture and analysis. Their paper explores both the impact of the model and the perspectives of staff involved. The authors posit that that universities "should engage in evidence-based knowledge exchange with online specialists [learning designers] to ensure a future-focused cohesive university experience".

Finally, Steven White and Kate Borthwick consider the opportunities and challenges of working with external partners in the development of MOOCs and the changes to roles that emerge when academic activity is unbundled. They explore the important implications of unbundling for academic workload and the changing nature of learning designer expertise, particularly as it relates to online curriculum.

\section{Concluding thoughts}

We are excited by the emerging models that are showcased here. We are confident the papers make a valuable and timely contribution to the wider conversation about partnership and unbundling, especially as increased interest in these approaches is likely in a changing higher education system. There are clearly opportunities for creative and transformational thinking and practice as we move towards what Salmon (2019, p. 104) describes as a Education 4.0, which is characterised by "ubiquitous connectivity and the symbiosis between humans and machines". The papers in this special issue point us towards the potential in that respect, while fully illuminating the challenges involved.

We know universities already work with external partners in a variety of ways. What has changed more recently is that both sides are permeating more strongly into each other's territories, and that the goals of absolute core business is shifting in response. For commercial businesses, the desire for partnerships to work out successfully is clearly no less than for universities; however, commercial concerns and sensitivities about operating practices and models, the appropriateness of the use of data, external publicity and commentary and the increasingly crowded commercial online programme management global market make private-public partnerships a challenging research arena.

Yet, even given these challenges, this issue considers the benefits from all partners' perspectives, with an emphasis on responsibilities in relation to achieving commercial and academic outcomes. We provide insight into new and effective arrangements that build capability and capacity for partners to work together as an entity. We point to potential for partnerships to develop capability in online learning, adding value and sometimes unique characteristics and competencies, thus creating a potential 3rd culture, a blend of commercial and public enterprise delivering the best of both worlds for the benefit of learners. Looking ahead to a challenging post-COVID world, it is essential to deliver sustainable, quality digital education and good student outcomes. We hope we offer exploration of the opportunities to ensure the survival of the traditional university and possibilities for higher education to thrive in a myriad of ways, working with partners. Higher education has a great need to regain its critical place for learning in sustainable online futures.

\section{Acknowledgements}

A huge thanks goes to the associate editors for their high-quality editorial work that contributes strongly towards our excellent and highly regarded journal. The associate editors are highly experienced researchers who expertly shepherd papers through the review process and volunteer their time to the journal. We thank the AJET copyeditors who work closely with the lead editors to ensure a high standard of final proofs is maintained. We also extend heartfelt thanks to our international team of reviewers who perform an invaluable service to the journal. 


\section{References}

Lewis, N., \& Shore, C. (2019). From unbundling to market making reimagining, reassembling and reinventing the public university. Globalisation, Societies and Education, 17(1), 11-27. https://doi:10.1080/14767724.2018.1524287

Neely, P. W., \& Tucker, J. P. (2010). Unbundling faculty roles in online distance education programs. Contemporary Issues in Education Research, 3(6), 17-23. https://doi.org/10.19030/cier.v3i6.211

Oliver, B. (2019). Making micro-credentials work for learners, employers, and providers. Deakin University. https://www.assuringgraduatecapabilities.com/uploads/4/5/0/5/45053363/making-microcredentials-work-oliver-deakin-2019.pdf

Salmon, G. (2019). May the fourth be with you: Creating Education 4.0. Journal of Learning for Development, 6(2), 95-115. https://j14d.org/index.php/ej14d/article/view/352

Swinnerton, B., Ivancheva, M., Coop, T., Perrotta, C., Morris, N., Swartz, R., Czerniewicz, L., Cliff, A., \& Walji, S. (2018). The unbundled university: Researching emerging models in an unequal landscape. Preliminary findings from fieldwork in South Africa. In M. Bajić, N. Dohn, M. de Laat, P. Jandrić, \& T. Ryberg, T. (Eds.), Proceedings of the 11th International Conference on Networked Learning 2018 (pp. 218-226). http://networkedlearningconference.org.uk/abstracts/papers/swinnerton 23.pdf

Wang, W. (1981) The dismantling of higher education. Improving College and University Teaching, 29(2), 55-60. https://doi.org/10.1080/00193089.1981.10533678

Corresponding author: Henk Huijser, h.huijser@qut.edu.au

Copyright: Articles published in the Australasian Journal of Educational Technology (AJET) are available under Creative Commons Attribution Non-Commercial No Derivatives Licence (CC BY-NC-ND 4.0). Authors retain copyright in their work and grant AJET right of first publication under CC BY-NC-ND 4.0 .

Please cite as: Huijser, H., Fitzgerald, R., \& Salmon, G. (2020). Partnerships for scaled online learning and the unbundling of the traditional university [Editorial]. Australasian Journal of Educational Technology, 36(5), 1-4. https://doi.org/10.14742/ajet.6664 